\title{
Research into the Product Development Mode Based on Knowledge Appreciation
}

\section{Hao Fangmin}

School of Economics and Management, Beijing University of Posts and Telecommunications' Beijing 100876, China

13021123877@163.com

Keywords: Knowledge economy, "hardware + knowledge” development mode, knowledge product economy, product development mode.

\begin{abstract}
The global industrial structure is undergoing radical changes owing to the continuous development of emerging technologies including mobile Internet, Internet of things and big data, that is, from the predominance of hardware real economy to the co-existence of hardware and knowledge. In recent years, as the knowledge product appears on the stage, the knowledge economy has become a dark horse boosting the global economy. This paper will study the development patterns of representative companies in different phases by combining case analysis and comparative analysis, analyze their major development characteristics, and forecast the changes of corporate management modes in the current economic situation in line with the new technical tools like Internet and big data.
\end{abstract}

\section{Introduction}

As the curtain descended on the $4^{\text {th }}$ World Internet Conference in Wuzhen, the digital economy enters the public view again. Relevant data display that the scale of digital economy in China has reached 22.5 trillion yuan by 2016, with a year-on-year increase of $18.9 \%$, and occupied $30.3 \%$ of the GDP. The Internet is undoubtedly the most powerful tool for the development of digital economy. Hence, its expansion in size and increase in penetration rate have been key factors in the steady growth of the digital economy. From the figure below, China's Internet penetration rate has maintained a steady growth of about $3 \%$ since 2012. According to the $39^{\text {th }}$ China Statistical Report on Internet Development published by CNNIC, by December 2016, the number of Chinese netizens has reached 731.25 million, the new netizens amounting to 42.99 million this year. The Internet penetration rate is up to $53.2 \%$, with an increase of $2.9 \%$ compared with the statistic data at the end of 2015. At the same time, there has been a rise in the number of global netizens. From 2012 to 2016, although Chinese netizens constantly increase, its global proportion is declining, which reflects that there exist a huge number of potential users. On the whole, the ever-expanding netizen scale, steadily climbing Internet penetration rate, and the development strategies of reaching out to the world all provide more market potential for the digital economy.

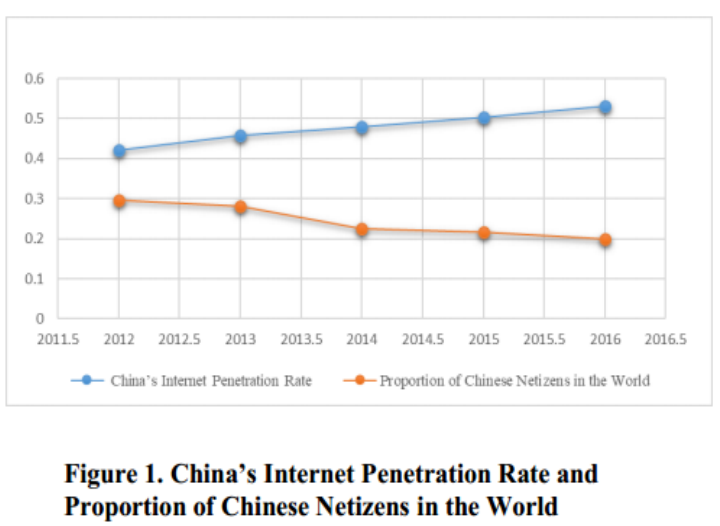

Among these netizens, 95.1\% are mobile Internet users, growing by 5\% year-on-year. In the future, 
mobile APPs are bound to face a great many users who, besides basic living needs, more thirst for knowledge and data; correspondingly, the digital economy, knowledge economy and other emerging economic forms will prosper. Such a market change, from supply-oriented to demand-oriented, further shapes the management modes of relevant enterprises. This paper analyzes the changes of management modes of typical corporations from the perspective of hardware real economy, hardware + knowledge development mode and knowledge product economy.

\section{Hardware Real Economy Development Mode}

Traditionally, the real economy is concerned with the national economy and the people's livelihood, for example, machinery manufacturing, textile processing and transportation. As the economic pillar of the national development, the real economy is of paramount importance to the government, enterprises and individuals. However, with the constant progress of social technologies and the emergence of new economic forms, the global real economy has found itself in an unprecedented predicament; the status quo of China, as a giant of real economy, is even more serious. Right now, the real economy in China has been constrained by problems including a lack of development motivation, slow pace of industrial upgrade and a large amount of capital flowing to the speculative market from industries. Most notably, since the proportion of the tertiary industry keeps rising, the real economy has gradually weakened, so do the emphases on it from every level. Although afterwards there are policies aiming at improving the real economy, the decline of the real economy can no longer be ignored.

Eastman Kodak Company, used to be one of the largest film suppliers in the world, had brought about a revolution to the photographic industry as soon as it was established. Its market share had once skyrocketed to $75 \%$, and later in the 1970s, its revenue exceeded 4 billion dollars, accounting for $90 \%$ film market and $85 \%$ camera market. So to speak, Kodak, yielding unusually brilliant achievements, had dominated the photographic industry in the last century. Nevertheless, such predominance came to an end in the late $20^{\text {th }}$ century and early $21^{\text {st }}$ century. In 2001 , the advent of digital cameras and the soaring market demand put the traditional film industry into a survival crisis: no one showed any interest in "traditional cameras" that Kodak relied on and the global demand for the film quickly shrank with a decrease rate up to $10 \%$ per year. Only in one year, the sales volume of digital cameras surpassed that of traditional cameras, consequently toppling Kodak from the throne. In order to address this urgent problem, a series of reforms were carried out inside the company but the conservative management, counting on luck, still missed the golden time of digital cameras. As a result, the company was thrown under a difficult circumstance owing to its plummeted market share, and not surprisingly, filed for bankruptcy protection in 2012. Today, some of its products can still been found on the market, yet when compared with Sony and Canon of Japan, Kodak's market position has been far worse than before. How did it happen? Its overconfidence in the market share and the development ability had made Kodak underestimate its competitors. In fact, early in 1986, Kodak had produced the first 1.4 megapixel electronic image sensor and possessed a lot of relevant patents in this field. Nevertheless, instead of taking the lead, it tried to squeeze the final benefit of the film market and enjoy a tailwind of the digital camera at the same time even after competitors had established a foothold and got into high gear in the new market. As it turned out, this opportunism choice was the reason why Kodak was discarded by the overall environment and market. During its filing for the bankruptcy protection, Kodak could still take some measures so as to keep abreast of the market development, but unfortunately, it again failed to seize the fleeting opportunity.

It is really sorry to witness that Kodak, a superior member of the real enterprises in the last century, ended up with bankruptcy. Important as innovation is, it is crucial to figure out the future direction of the international progress, make timely adjustments, abandon former glory if necessary, strive to keep pace with the time and maximize the benefit of every capital. 


\section{3. “Hardware + Knowledge” Development Mode}

As mentioned above, the value of a product used to be determined by the enterprise when the hardware real economy took a dominant position, that is, the enterprise created value in the course of production and delivered the value to customers in market exchange. Therefore, customers were the end of value chain. Being passive recipients of products, they could only choose from products but not design or develop a product in accordance with their own needs and preferences. Nevertheless, in the post-industrial era which boasts flourishing economy, upgraded technologies, abundant social materials and diverse user requirements, customers gradually become the value creators of products. Since their ideas and preferences inject fresh inspirations into product development, they turn into real participants and founders of new products rather than mere passive recipients, who, standing on the same level with corporations, interact and communicate with enterprises to add personalized elements. Seemingly simple, this role change is actually the recognition of different values. To be more specific, only tangible and visible products are regarded as value in the real economy, while today, knowledge, thought and other invisible "substances" are exerting their unique economic value. Consequently, market is no longer a place solely for material exchange between consumers and manufacturers, but a site for their idea collision, exchange and value addition as well. Such a transformation has ushered in the era of knowledge economy.

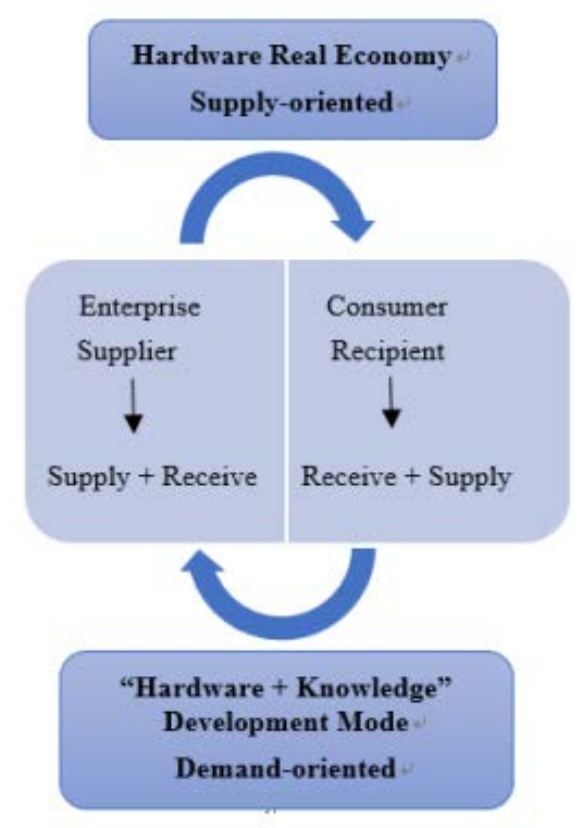

Among companies pursuing value co-creation via economic transition, Xiaomi is the most famous and successful one which sees its leadership role in the domestic mobile phone industry. On the basis of its business mode "hardware + software + service", it takes smart products as carriers and virtual brand communities as well as social media as interaction platforms, provides various services for consumers, and well integrates its products and services at each stage of lifecycles, thus forging an open product service system ${ }^{[1]}$. This value co-creation philosophy has spanned its entire development process. Established in April 2010, Xiaomi pioneered the use of Internet to make in-depth exchanges with fans before designing MIUI, a free mobile phone operating system based on Android, whereby it proposed the product idea "Born for You, Burn for MI". ${ }^{[3]}$ Specifically, during the product design and development, Xiaomi collects consumers' appeals from a wide range of channels, so as to master their actual needs and preferences, add functions they desire, and accordingly improve the product through repeated discussions and trials with consumers. This measure, to some extent, heightens Xiaomi's brand awareness and attracts many potential consumers to its upcoming products. Having got actively involved in the design and development, these people attach great importance to the final presentation 
of products; in other words, they are the initial core users of Xiaomi's products, who will exercise their social influence to expand Xiaomi's brand influence and help it establish a foothold in the market. Meanwhile, as social tools are necessary to obtain more initial core users and encourage user participation, Xiaomi creatively produces a series of value interactive platforms. The online interactive platforms include Miliao, Diandi System, MIUI website and Xiaomi BBS, coupled with social media such as WeChat, Weibo and Baidu Tieba; the below-the-line platforms incorporate Socialclub, Mipop, MI Service Center etc. Through the close communication, not only can Xiaomi receive the latest user experience and capture current consumer demands, but it upgrades users' experience value and catches regular users while drawing more potential users. Consequently, it constantly gains in market influence and brand popularity to occupy the advantageous position in market.

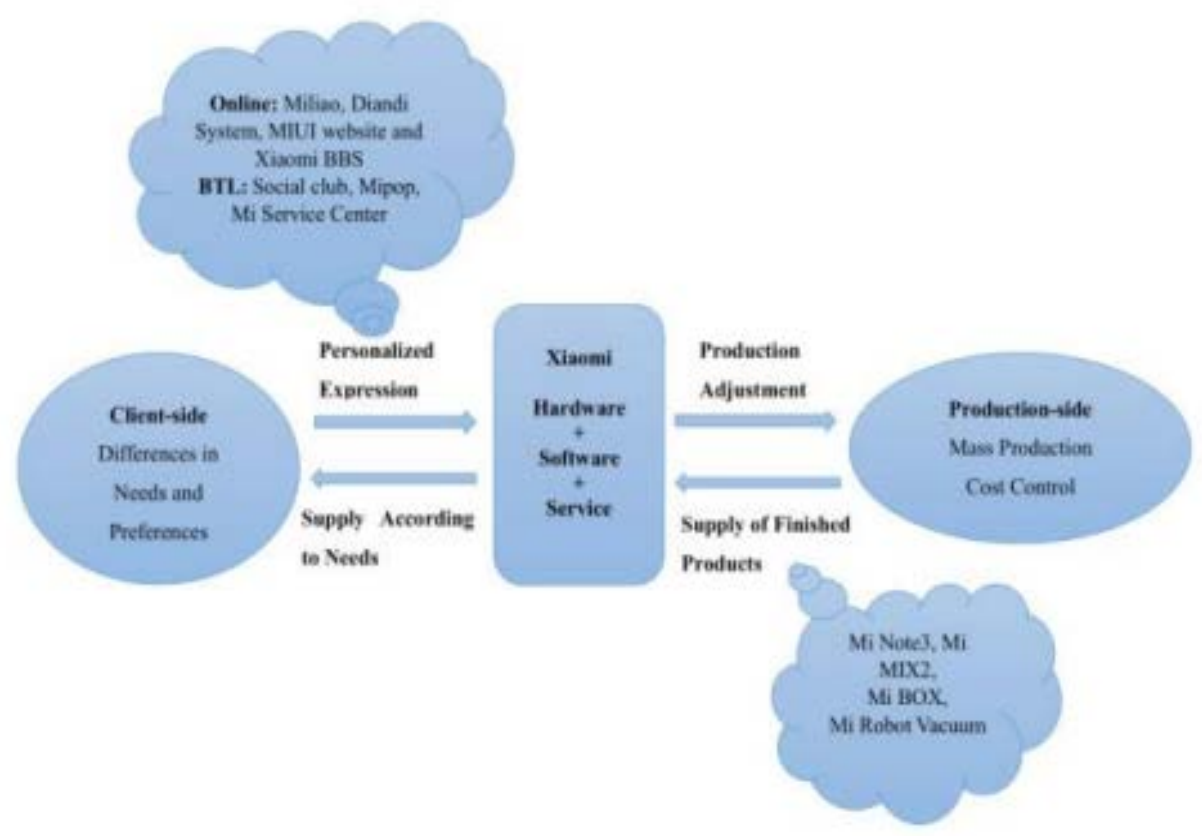

Relevant data show that Xiaomi has enjoyed a compound growth rate far surpassing the average industrial rate since its establishment in 2010. In 2014, claiming a market share of $12.5 \%$, it took up the No.1 in the domestic smart phone market; meanwhile, as its market value shot up from 250 million dollars to 45 billion dollars, Xiaomi became the unlisted technology company with the highest value worldwide. Although right now it does not develop as fast as before, we cannot deny that its development strategy has enabled it to grab the market at early stage and increase its user adhesiveness (up to $42 \%$ users repeatedly buy more than $3 \mathrm{Mi}$ phones) which is of paramount importance in the ever-changing electronics market.

The success of Xiaomi proves that knowledge can create much more value than anticipated. For Xiaomi itself, the ideas of consumers can build up a large repository--how to take advantage of this treasure house is the crux of its future development. Certainly, this does not mean that Xiaomi has abandoned its former hardware value. According to related statistics, Xiaomi ecological chain with MI phone as the core has invested in 77 companies by the end of 2016, and its revenue from smart hardware has risen above 15 billion yuan. After the development mode of "hardware + knowledge" has been fully tested in reality, the intangible resources like knowledge make their debut as the new value.

If the phenomenal rise of Xiaomi is mainly attributed to its grasp of the economic and times opportunities, then the successful transformation of Haier is the epitome of real enterprises' reform. Being a representative of Chinese manufacturing corporations, Haier actually illustrates the way of reform taken by most real enterprises in China. Since Haier came out first in the worldwide large household appliance market eight years ago, it has maintained the high standard till today, for example, by 2016, it has "kept the industry growth rate in the first place for five consecutive years", 
"doubled the sales volume of household central air-conditioner for three consecutive years", and "acquired the top position in the magnetic levitation market with a market share of 81\%". These achievements are closely related with the changes in Haier's strategic philosophy. At that time, the innovation and popularization of Internet technologies had imperceptibly altered the relation between traditional enterprises and customers. With more and more communication methods, enterprises were not only product suppliers anymore while customers were not passive recipients either, which required Haier to transform from production-oriented into service-oriented. And Haier did seize the best time to reform from the previous B2C mode (manufacturer-centered, large-scale production/promotion, and low-cost competition) into the C2B mode (consumer-centered, personalized marketing, flexible production and precise service). The change of its guiding ideology inevitably led to adjustment of necessary links in the process of corporate operation like production-sale mode, marketing mode and organization mode. First of all, the production-sale mode turns from the traditional production-inventory-sale pattern to supply according to demand with zero stock, which, in addition to lowering the production cost and ensuring the quality, tailors products to suit customers' needs, indirectly increases their reliance on Haier, develops potential users and thereupon provides a favorable market for the launch of new products. As for the marketing mode, Haier implements "zero-distance between the virtual and the real network". The virtual network stands for the social network, such as Weibo and WeChat, which is used to attract hardcore fans, thus laying a certain market foundation; the real network means to improve the marketing, logistics and service networks, in a bid to strengthen the loyalty of regular customers and appeal to potential users by dint of high quality services and products. Last but not least, the organization mode refers to its transition from a "triangle" to an "inverted triangle", that is to say, the autonomous management team. Instead of the production order determined wholly by senior managers and implementation from top to bottom, this mode highlights the feedback from users and opinions of front-line staff, asks the management for strategic guidance, and obtains support from a variety of middle departments. [2] Since every team consists of members from different departments, like salespeople, planners, supply chain personnel and finance personnel, the corporate resources can be integrated and utilized in a more efficient way. Meanwhile, with the same goal, members take charge of the whole process from mastering to meeting users' needs, in order to actualize the "win-win situation between staff and order" in the Internet era, together with management modes like "one man and one order, one order and one pay, one man and one pay" and "win-win situation".

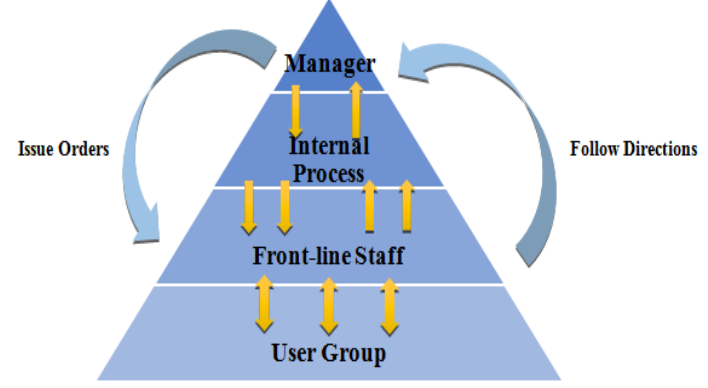

Traditional “Triangle” Organization Structure

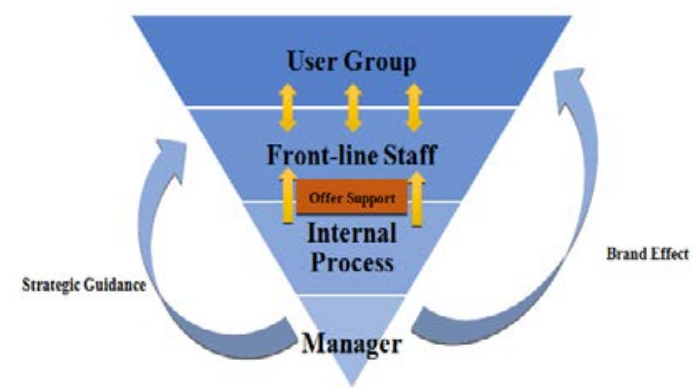

Haier’s “Inverted Triangle” Organization Structure

The successful transformation of Haier offers a good example to the current real economy in China. Given the increasingly stronger global connections and dramatic changes in resources allocation brought by the sharing economy, the real economy is facing a new turning point in its progress. In the future, real enterprises are likely to put more brand-new issues on their agendas: how to occupy an advantageous position in the huge incremental market? How to closely combine their development with the Internet? How to grasp the blaze of publicity and stimulate the profit growth by means of innovation? In the case of Haier, it is the timely changes and comprehensive reforms coming from 
above in the wave of the Internet that enable Haier to constantly interact with customers and innovate solutions accordingly; consequently, it maintains its supremacy in the large household appliance industry and forges into the lead in the household appliance industry at the same time.

Taking a look at the development of Xiaomi and Haier in the past five years, we can see that although their starting points vary, both of them well integrate the real economy and the virtual economy. Be it in the strategic guidance or in the operation mode, changes should all conform to the trends of times, particularly, the unceasing innovation and popularization of Internet technologies as well as the emergence of the sharing economy. Therefore, corporations must make changes to its original development mode. Only by putting forth novel strategies in accordance with the actual situation can companies stand firm and make steady strides in the ever-changing market environment.

\section{Knowledge Product Economy}

The knowledge product, just as its name implies, makes profits only by knowledge. Totally different from traditional manufacturing enterprises whose products act as the value carriers, namely, their value is visible and tangible, or their value relies on entities and presents specific manifestations, invisible and impalpable knowledge products mostly count on perception and resonance. From another point of view, previous products, focusing on material demands of customers, can only bring limited spiritual satisfaction; on the contrary, the usefulness of knowledge products wholly depends on consumers' mental experience-whether they acquire knowledge or fulfill spiritual needs. The improvement of material life has diverted people to paying more attention to the high-quality spiritual life, so a variety of knowledge products come into being. At present, Weibo, Zhihu and other knowledge products similar to social platforms have been widely recognized by the public and carried out smooth operation; besides, there are some application-oriented knowledge products: Youdao Translation (translation among different languages), XimalayaFM (radio broadcasting — spread of audio books), Dedao (charged courses given by experts), and Jinri Toutiao (rapid spread of news). These products have been considered indispensable in people's daily life, and the huge market also speaks volumes for people's growing demands for knowledge products. In the meantime, their management modes are truly unique due to discrepant product forms from those in hardware real economy. The following part takes Weibo and Zhihu as study cases to dissect their management patterns respectively.

Weibo, as a representative of emerging media, is significantly different from traditional social media in terms of user experience, content production, information interaction, etc. which therefore causes considerable changes in its profit and marketing models. The statistics state that by 31 March 2017, Weibo has aggregated about 340 million monthly active users, overtaking Twitter to become the world's largest independent social media company. The strong data support grants Weibo high profitability. In the first quarter of 2017 , its revenue has reached 1.37 billion yuan, with a year-on-year growth of $76 \%$, and its net profit has risen by $278 \%$ over the same period last year, both of which exceed the average expectations of analysts in the Wall Street. The continuous increase of user number and earning power are intertwined with its unique operation mechanism. Apart from free service, vast information and anonymity, Weibo's most effective marketing strategies are the cooperation with opinion leaders - by resorting to the fan economy, it properly maintains the stability and growth of users. On Weibo, ordinary people can get in close contact with their idols or elites from all walks of life, fulfilling spiritual needs by mastering the latest news. This feature, furthermore, exploits a new earning point: online celebrities who extend Weibo's industrial chain. On the Double 11 Shopping Day this year, the sales volumes of three online celebrities' Taobao stores all soared up to more than 100 million yuan within one day. The skyrocketing transaction indexes even allowed these stores to compete with other well-known brands at home and abroad. This is indeed unimaginable in the age of real economy, considering its restrained promotion schemes. Additionally, the fan economy has made the advertising revenue an important source of income. At the end of 2016, Weibo's annual advertising income has reached 571 million dollars, increasing by $42 \%$ compared with the last year. Thereafter, it successively launches short video, real-time content consumption and 
other new functions which attract more small and medium enterprises to put advertisements on Weibo for the sake of sales growth.

Another example is Zhihu which bear similarities and differences with Weibo. Set up in 2010, Zhihu has 69 million registered users who have created 15 million questions, 55 million answers and 250 thousand topics by March 2017. Currently, it is the only high-quality knowledge social platform in Q\&A form in China. ${ }^{[3]}$ Traditional marketing strategies, for the purpose of attracting the majority of people, usually overlook differences between groups and adopt the same scheme for product promotion. As regards Zhihu, it identified the genuine elites as its target group at the preliminary stage owing to the uniqueness of knowledge, with an eye to build a high-end Q\&A community. Afterwards, by publicizing its high-end, high-quality, effective and practical notions, Zhihu successfully involves ordinary users in and expands its user range. Its special characteristics also earn it a good reputation and brand image which are key factors for corporate advertisement. Therefore, the advertisement revenue has become a source of profit apart from user registration, work publishing, industry summit and service to headhunters.

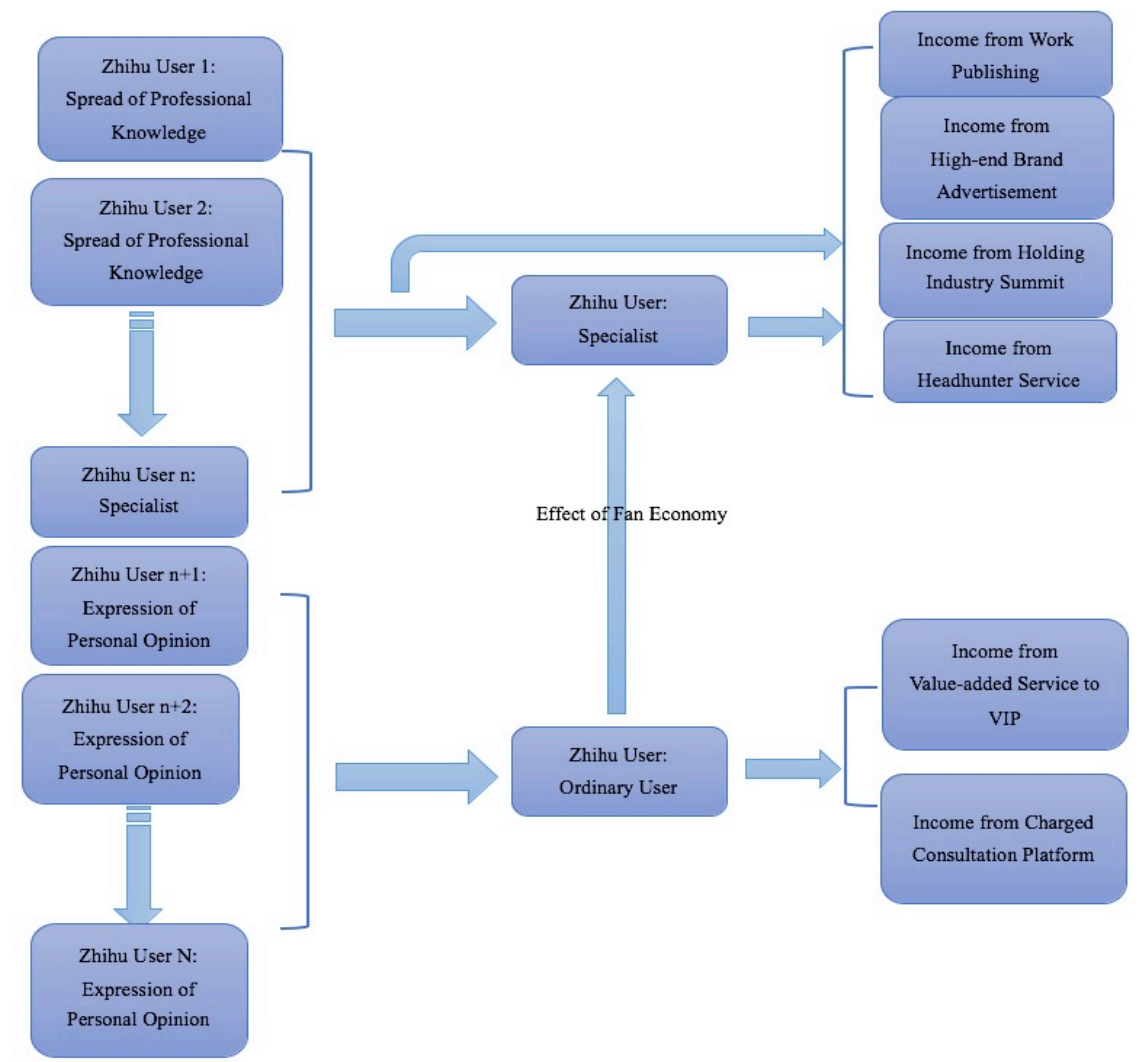

Taking a look at the marketing strategies of Weibo and Zhihu, we can find that they both commercialize and materialize virtual concepts such as knowledge. As a result, the originality and sharing of knowledge serve as their earning point. Considering their online and popular platforms, their marketing strategies should conform to the characteristics of network communication, so as to create more network value. In addition, these emerging Internet companies no more stick to the traditional employment methods; instead, they highlight practical work performance and spiritual rewards in addition to promotion and salary increase. In these enterprises, active thinking and innovative idea play essential roles in selecting and assessing employees, in other words, they want employees who can put forth valuable ideas or concepts in the future work. This method is highly conducive to the long-term development of a company.

\section{Summary}

With the continuous improvement of times and the ceaseless progress of technology, particularly emerging economic forms including digital economy and knowledge economy, management modes of enterprises are inevitably experiencing changes: how to apply new technologies, new media and 
new platforms, and how to mobilize customers for good interaction between corporations and customers are now the key factors for enterprises to open the market and achieve sustainable business growth. On the other hand, the real economy is now exposed to unprecedented harsh conditions, for instance, the surge of production factor costs, especially the labor cost far exceeding expectations due to the disappearance of demographic dividend; the heavy corporate tax; the low innovative capacity, together with the imperfect financial market and intellectual property protection system. When these issues all put the hardware real economy into a plight, the new real economy becomes the major power boosting the future economic growth. Hence, the crux of development lies in the innovative and pioneering spirit: to dig out the greater market potential, adjust the entire development direction timely, take advantage of existing preferential policies, information, technologies etc. for the purpose of fostering development. Through the above case analysis, we can see that knowledge-based enterprises such as Zhihu and Weibo are on the rise, and there will be a large number of knowledge-based enterprises in the future. The emergence of new-type enterprises will inevitably bring about huge market repercussions and excess profits, but a series of unexpected problems ensued, such as the protection of intellectual property. In the past era of real economy, in most cases, intellectual property was only concerned by some groups, but Nowadays, with the rapid development of new technologies such as Internet and big data, intellectual property is closely related to each individual. Therefore, how to use knowledge to create wealth and protect intellectual property from infringement will be a major issue facing this type of enterprises. It will be one of the research directions in the field of future business management for this type of enterprises. Apart from that, the real economy will not decline all the time. Although some enterprises are gradually failing in transition, it is undeniable that there are still successful cases of transformation of real enterprises such as Wanda, and this trend is gradually being strengthened. The reasons for the success of these enterprises and the reasons for the universality of these reasons will be more research value, and can provide the theoretical support for the future transformation and development of enterprises.

The knowledge economy and digital economy have provided diverse modes of economic development, unfolded a huge potential market, and supplied more tools and ideas to the real economy. In no case will the real economy decline all the time, and new economic modes like the knowledge economy will prosper, so the continuous optimization of the overall economic structure is bound to promote the sustainable and steady growth. In this process, enterprises should have market acumen, catch up with cutting-edge technologies, and take the lead in adjusting management modes, in a bid to stay abreast with the overall economic trend, jump at every opportunity and respond to any challenge.

\section{References}

[1] Zeng Jinglian and Jian Zhaoquan. Product Service System in the Internet Environment: Perspective of Enterprise-Customers-Environment Value Co-creation, J. Forum on Science and Technology in China. 8(2017) 87-93.

[2] Anonymity. Framework of Haier Mode, J. China Internet Week. 4(2012) 30-31.

[3] Chen Zhicheng. Kodak’s Bankruptcy-A failed Transformation, J. China Business \& Trade. 21(2012) 69-70.

[4] Li Wenxiong. Case Study of Kodak's Digital Transformation, D. Guangzhou: South China University of Technology. (2012) 1-61.

[5] Dai Tianjing, Tang Guliang and Peng Jiajun. The Dynamic Capability Improvement, the Inverted Organizational Structure and the Integration of Management Control System-an Explorative Case Study Based on ZZJYT of Haier Group, J. China Industrial Economics. 2 (2012) 128-138.

[6] Zhou Qihong. Analysis of Community Economy and Community Business Mode, J. Journal of Commercial Economics. 11 (2017) 19-21. 
[7] Zeng Fansen. Analysis of Zhihu's Marketing Strategies in Sharing Economy, J. Economic \& Trade. 20(2017) 152-154.

[8] Xu Jin and Liang Miya. On Ant Effect and Digital Economy--Analysis and Application on the Negative Proposition of Herd Effect, J. Economist. 4(2017) 27-35. 